\title{
Quantitative analysis of the IgG and IgG subclass immune responses to chromosomal Pseudomonas aeruginosa $\beta$-lactamase in serum from patients with cystic fibrosis by western blotting and laser scanning densitometry
}

Tine D Petersen, Oana Ciofu, Tacjana Pressler, Birgit Giwercman, Svend S Pedersen, Niels Høiby

\begin{abstract}
Background - Antibodies against chromosomal B-lactamase of Pseudomonas aeruginosa (aßab) are markers of the development of resistance of $P$ aeruginosa to $\beta$-lactam antibiotics in patients with cystic fibrosis and chronic lung infection. The role of these antibodies in patients with chronic lung infection with $P$ aeruginosa was further investigated by correlating the aßab IgG subclasses with pulmonary function in patients with cystic fibrosis.
\end{abstract}

Methods - Immunoglobulin G (IgG) and IgG subclass aßab were investigated by western blotting and quantified by laser scanning densitometry. A longitudinal study on 43 consecutive patients with cystic fibrosis who developed chronic lung infection with $P$ aeruginosa was performed. Results - IgG subclass aßab appeared in all patients with chronic infection with $P$ aeruginosa. Eleven years after the onset of infection all the patients had IgG $_{1}, 79 \%$ had $\mathrm{IgG}_{4}, 56 \% \mathrm{IgG}_{2}$, and only $16 \%$ of the patients had $\mathrm{IgG}_{3}$ aßab. The $\mathrm{IgG}_{1}$ and $\mathrm{IgG}_{4}$ aßab appeared first, and more than $50 \%$ of the patients were $\operatorname{IgG}_{1}$ and $\operatorname{IgG}_{4}$ aßab positive within 2-3 years of the onset of infection, but IgG $_{2}$ positivity only appeared after seven years and $\mathrm{IgG}_{3}$ remained absent from most of the patients. The median aßab levels increased during chronic infection: 100-fold for $\operatorname{IgG}_{1}, 22$-fold for $\operatorname{IgG}_{2}$, and 45-fold for IgG $_{4}$. A 16-fold increase in the $\operatorname{IgG}_{3}$ aßab levels was detected in the six patients who developed IgG $_{3}$ aßab. In the first four years of the chronic infection the aßab titres were higher in patients with good lung function than in those with poor lung function.

Conclusions - The association of a weak $\mathrm{IgG}_{3}$ and a strong $\mathrm{IgG}_{4}$ aßab response suggests that the contribution of aßab antibodies to lung diseases mediated by immune complexes might be less important than other antipseudomonal antibodies. A beneficial neutralising effect of the aßab antibodies on the antibiotic destroying enzymes may be an additional factor.

(Thorax 1996;51:733-738)
Keywords: cystic fibrosis, IgG, antibodies, Pseudomonas aeruginosa, $\beta$-lactamase.

In most cystic fibrosis centres the occurrence of Pseudomonas aeruginosa strains resistant to $\beta$-lactam antibiotics is a common problem in patients with chronic $P$ aeruginosa lung infection. ${ }^{12}$ The most important resistance mechanism consists of large amounts of chromosomal $\beta$-lactamase produced by stably derepressed $P$ aeruginosa strains, as shown previously in our population with cystic fibrosis. ${ }^{34}$ These strains are selected in vivo by antibiotic pressure. ${ }^{56}$ Besides this mechanism, the permeability barrier and the drug efflux mechanisms are also involved in the development of resistance to $\beta$-lactam antibiotics. ${ }^{78}$ While these two mechanisms mainly explain the intrinsic resistance of $P$ aeruginosa to a wide array of antimicrobial agents including $\beta$-lactams, ${ }^{9}$ the production of chromosomal $\beta$-lactamase is mainly responsible for the high levels of resistance to $\beta$ lactam antibiotics encountered in strains collected from patients who have been intensively treated with ureidopenicillins and third generation cephalosporins. ${ }^{8}$

High levels of $\beta$-lactamase activity have been found in the sputum of patients with cystic fibrosis, ${ }^{10}$ which could lead to inactivation of $\beta$-lactam antibiotics. Antibodies against the chromosomal $P$ aeruginosa $\beta$-lactamase (a $\beta \mathrm{ab}$ ) have been detected in the serum and sputum of patients with cystic fibrosis and chronic lung infection with $P$ aeruginosa. ${ }^{11}$

The presence in the serum of both $\beta$-lactamase activity and $a \beta a b$ has led to several hypotheses on their clinical significance. One theory emphasises the potential protective role of the $a \beta a b$ antibodies by inhibiting the extracellular $\beta$-lactamase and thus improving the effect of the $\beta$-lactam antibiotics. However, another hypothesis emphasises the possible destructive role of these antibodies by participating with the extracellular $\beta$-lactamase in immune complexes which could play an important part in the pathogenesis of airway injury in cystic fibrosis by mediating type III hypersensitivity inflammatory reactions. ${ }^{12}$

We have previously shown that $\mathrm{a} \beta \mathrm{ab}$ antibodies are markers of the development of re- 
sistance of $P$ aeruginosa in patients with cystic fibrosis and chronic bronchopulmonary infection. ${ }^{13}$ In order to clarify some of the questions raised on the clinical significance of $a \beta a b$ antibodies we have conducted a more detailed investigation of the immune response to chromosomal $\beta$-lactamase.

The IgG subclasses have different abilities to participate in phagocytosis and complement activation. ${ }^{14}$ We therefore investigated the development of different IgG aßab subclasses during the course of chronic infection with $P$ aeruginosa. An inverse correlation has been described between the $\mathrm{IgG}_{2}$ and $\mathrm{IgG}_{3}$ antibodies to $P$ aeruginosa cell sonicate, alginate, outer membrane proteins, lipopolysaccharide (LPS) and lung function, ${ }^{15-18}$ so we also investigated whether there was a correlation between lung function and the IgG subclass pattern of $\mathrm{a} \beta \mathrm{ab}$.

\section{Methods \\ PATIENTS WITH CYSTIC FIBROSIS}

The diagnosis of cystic fibrosis was based on accepted criteria including genotype, abnormal sweat electrolyte levels in repeated tests, and exocrine pancreatic insufficiency. After diagnosis, the patients with cystic fibrosis were monitored monthly at the Danish Cystic Fibrosis Centre at Rigshospitalet. Data on the clinical condition and sputum bacteriology have been recorded prospectively since 1970 . The following definitions were used to describe the patients with regard to $P$ aeruginosa infection: non-infected $(\mathrm{CF}-\mathrm{P})$ were patients without growth of $P$ aeruginosa in their sputum at the regular monthly examinations and with no increase in serum antibodies to $P$ aeruginosa (less than two precipitin bands against $P$ aeruginosa sonicated antigen); and chronically infected $(\mathrm{CF}+\mathrm{P})$ were patients in whom $P$ aeruginosa was present in the sputum at each monthly examination for more than six months or who had more than two precipitin bands. ${ }^{19}$

Pulmonary function (forced vital capacity (FVC) and forced expiratory volume in one second $\left(\mathrm{FEV}_{1}\right)$ ) were determined at each monthly visit using an electronic spirometer (Spirotron, Dräger, Denmark). All values were expressed as percentage of the expected values according to height and sex. The individual values in this study were the mean of all results in one year during the observation period. Poor lung function was defined as an $\mathrm{FEV}_{1}$ value of $<40 \%$ of the predicted value and good lung function as an $\mathrm{FEV}_{1}$ value of $>70 \%$ predicted.

For the purpose of the present longitudinal study, multiple serum samples (8-14 samples/ patient) were obtained at intervals of six months to one year from 43 consecutive $\mathrm{CF}+\mathrm{P}$ and 11 age matched $C F-P$ patients. The age of the patients at the onset of the chronic infection was evenly distributed between 0.8 and 29 years (median 10 years). The $C F+P$ samples covered the pre-infection period and the early and late stages of chronic $P$ aeruginosa infection. Seven of the $43 \mathrm{CF}+\mathrm{P}$ patients had chronic infection with a sensitive strain, a resistant strain being only intermittently isolated. From the 36 patients chronically infected with a resistant strain, nine had poor lung function and nine had good lung function. These were matched for age at the onset of the chronic infection and intensity of the treatment with $\beta$ lactam antibiotics. The rest of the patients with $\mathrm{CF}+\mathrm{P}$ had intermediate lung function. Since 1976 all the chronically infected patients with cystic fibrosis have been admitted to the centre every third month for a two week intravenous course of antipseudomonal antibiotics consisting of a combination of tobramycin and a $\beta$-lactam antibiotic. ${ }^{20}$

\section{HEALTHY CONTROLS}

In order to establish normal values for the assay, serum samples from 39 consecutive healthy controls with no history of $P$ aeruginosa infection were investigated. The median age (range) for 20 children was $11 \cdot 7$ years $(1 \cdot 1-$ $18 \cdot 7)$ and for 19 adults was 27 years (18-53 years).

\section{$\beta$-LACTAMASE AND MURINE MONOCLONAL} ANTIBODIES

$\beta$-lactamase from $P$ aeruginosa was produced and purified as reported previously. ${ }^{13}$ Monoclonal antibodies were made and antibodies from clone 3G2A11F7/07-1993 were used for the experiments. ${ }^{113}$

\section{SDS-PAGE AND IMMUNOBLOTTING}

All the serum samples were tested by immunoblotting. Purified $\beta$-lactamase was subjected to sodium dodecylsulphate-polyacrylamide gel electrophoresis (SDS-PAGE) on a $12.5 \%$ acrylamide running gel and $5 \%$ stacking gel. ${ }^{21}$ Samples were denatured before loading by heating to $100^{\circ} \mathrm{C}$ for five minutes with an equal quantity of sample buffer containing $2.5 \% \mathrm{w} / \mathrm{v}$ SDS. The loading of $\beta$-lactamase was $6.84 \mu \mathrm{g}$ protein $/ \mathrm{cm}^{2}$ of the top surface. The antigen was transferred from polyacrylamide gels to nitrocellulose paper $(0.45 \mu \mathrm{m}$ BA 85 cellulose nitrate, Schleicher and Schuell, Dassel, Germany). ${ }^{22}$ Blotting was carried out on a semi-dry blot apparatus (JKA-Bioterm) at $0.8 \mathrm{~A} / \mathrm{cm}^{2}$ for 90 minutes. The protein transfer on the nitrocellulose paper after blotting was checked by overnight Coomassie staining of the gel (Coomassie blue (Sigma), $0 \cdot 1 \% \mathrm{w} / \mathrm{v}$ in methanol $50 \% \mathrm{v} / \mathrm{v}$ acetic acid $10 \%$ ) and compared with a similar gel which had not been blotted. The unbound sites from the nitrocellulose paper were blocked by 30 minutes incubation with Tris- $\mathrm{HCl} 0.05 \mathrm{M}, \mathrm{NaCl} 0.1 \mathrm{M}$, $0.05 \% \mathrm{NaN}_{3}$ (TBS) containing $2 \%$ Tween 20 . Two mm wide strips of the nitrocellulose paper were then incubated overnight at $4^{\circ} \mathrm{C}$ with different serum samples.

Serum samples from patients diluted 1:20 and a standard sample (a reference pool of 10 cystic fibrosis serum samples selected from the late phase of infection with high antibody titres) diluted 1:1000 were used for incubating blots of the pure $\beta$-lactamase. All dilutions were carried out in TBS $/ 0.5 \%$ Tween 20 . The 


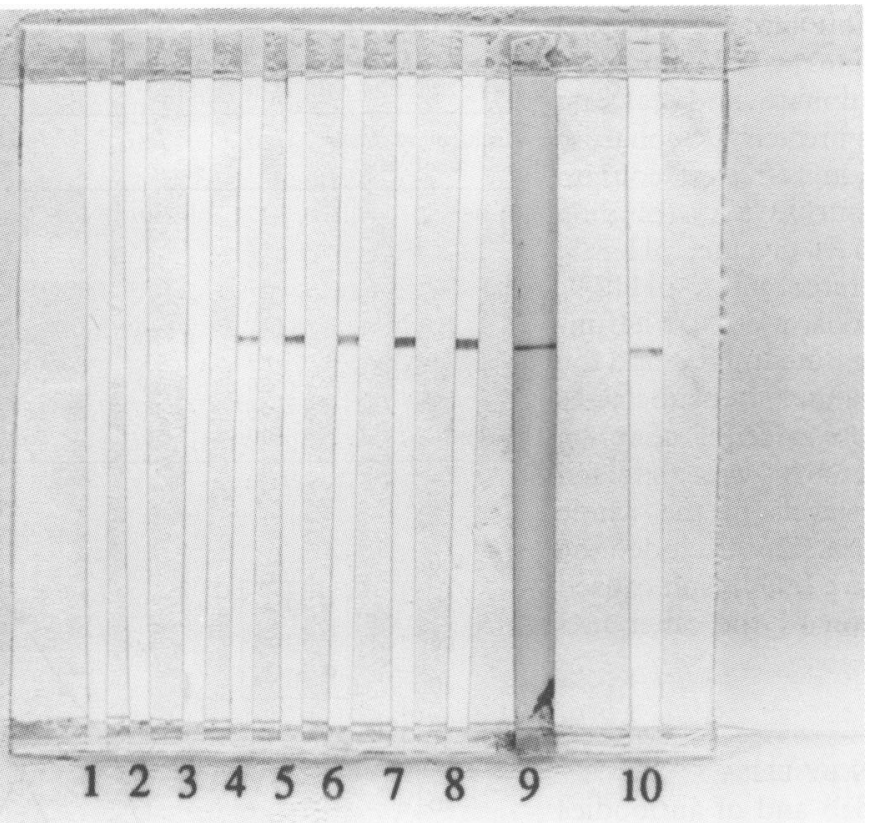

Figure 1 Immunoblots of $\beta$-lactamase incubated with serum samples collected during 1978-88 from a chronically infected patient with cystic fibrosis (lanes 1-8), with monoclonal antibody (lane 9), and with standard serum (lane 10).

nitrocellulose paper strips were washed thoroughly with the same buffer and incubated further for one hour at room temperature with peroxidase conjugated rabbit antihuman gamma chain specific antibody (P214, Dako, Copenhagen, Denmark) diluted 1:500. The colour was developed by DONS-TMB (dioctylnatriumsulphosuccinate-tetramethyl benzidine; Merck).

All IgG a $\beta a b$ positive samples in the screening assay were tested for the presence of different IgG subclasses by immunoblotting. The following dilutions were used for the tested serum samples: $1: 200$ for $\mathrm{IgG}_{1}, \mathrm{IgG}_{2}$, and $\mathrm{IgG}_{4}$, and 1:50 for $\operatorname{IgG}_{3}$ subclass determination. The standard sample was diluted as previously (1:1000 in TBS buffer). Peroxidase conjugated IgG subclass monoclonal antibodies (anti$\mathrm{IgG}_{1}: \mathrm{HP}-6069$, anti-IgG $: \mathrm{HP}-6014$, anti$\mathrm{IgG}_{4}: \mathrm{HP}-6025$, all diluted $1: 500$, and anti$\mathrm{IgG}_{3}$ : HP-6050 diluted 1:250; CLB, Amsterdam, The Netherlands) were used as secondary antibodies. In both assays controls with the murine monoclonal antibody against $\beta$ lactamase were run using rabbit anti-mouse IgG antibodies (P260 Dako, Copenhagen, Denmark) diluted 1:100 as secondary antibodies.

After incubation with the different secondary antibodies the nitrocellulose paper was thoroughly washed with TBS and the reactive sites were visualised with DONS-TMB. The antigen concentration, serum and antibody dilutions, and incubation times were chosen after preliminary investigations with serial dilutions of serum samples from chronically infected patients.

The immunoblots were allowed to dry at room temperature and, in order to avoid colour fading, they were scanned immediately using a Hewlett-Packard ScanJet IIP to measure the antibody response. The laser scan shows the antigen-antibody reactions as a number of peaks and the area under the curve corresponds to the levels of antibodies. The $\beta$-lactamase preparation was pure showing only a single band (peak) on the immunoblot with polyclonal (patient) and monoclonal serum samples (fig 1). This band corresponded to the band on a silver stained SDS-PAGE gel and to the reaction with nitrocefin (a chromogenic $\beta$ lactamase substrate). ${ }^{23}$ Isoelectric focusing showed a band with $\mathrm{pI}=8 \cdot 2$. Coomassie blue staining of the gel after blotting showed that there was complete transfer of the protein onto the nitrocellulose paper.

The area under the curve was analysed in a Compaq/Deskpro 466/33m, LTE, FASTART using the CREAM $4 \cdot 1$ program (Kem-EnTech, Copenhagen, Denmark). The results were expressed as units and calculated by dividing the intensity of the band obtained with the tested serum by the intensity of the band obtained with the standard serum multiplied by 10 , an arbitrary value given to the standard serum for all four subclasses.

\section{SPECIFICITY OF THE IMMUNOBLOTTING ASSAY}

The assay was antigen specific as demonstrated by absorption experiments. Incubation of serum samples with increasing amounts of $\beta$ lactamase led to the detection of decreasing amounts of IgG antibodies on the immunoblots. A reduction from $35 \%$ to $90 \%$ in the a $\beta a b$ detection was obtained by incubating the serum with increasing concentrations of $\beta$ lactamase from 0.2 to $1.2 \mu \mathrm{g} / \mathrm{ml}$ serum. Preabsorption with LPS and outer membrane proteins had no influence on the $a \beta a b$ titres.

The mouse monoclonal antibodies to human $\mathrm{IgG}_{1-4}$ were of World Health Organisation reference quality and displayed the desired specificity in immunoassays. ${ }^{24}$

\section{SENSITIVITY OF THE IMMUNOBLOTTING ASSAY}

Doubling dilutions of the $\beta$-lactamase from an initial loading of $20 \mu \mathrm{g}$ were separated on SDSPAGE, transferred to nitrocellulose paper, and allowed to react with patient serum samples diluted 1:20. The lowest amount of antigen which could be detected was $1 \mu \mathrm{g} / \mathrm{strip}$, equivalent to $0.2 \mathrm{ng}$ protein $/ \mathrm{mm}$.

To determine the lower level of detection of serum antibodies, doubling dilutions of the standard serum were allowed to react with $0.2 \mathrm{~cm}$ strips of nitrocellulose paper loaded with $\beta$-lactamase equivalent to $0.2 \mathrm{ng}$ protein/ $\mathrm{mm}$. At each dilution the density of the bands decreased until, at a dilution of 1:150 000, no band was visible. The highest dilution at which a reaction could be seen was 1:75 000 .

The sensitivity of this immunoblotting assay, expressed as the ratio between the serum quantity and the area on which the serum reacts, was $0.006 \mu \mathrm{l} / \mathrm{cm}^{2}$. By comparison, the sensitivity of the immunoblotting assay to detect antibodies against $P$ aeruginosa sonicate (standard antigen) was $0.014 \mu \mathrm{g} / \mathrm{cm}^{2},{ }^{21}$ which illustrates the high sensitivity of our assay.

Isolation of serum $\mathrm{IgG}_{3}$ from six patients with $\operatorname{IgG}_{3} \mathrm{a} \beta \mathrm{ab}$ and three patients without $\operatorname{IgG}_{3}$ 
$\mathrm{a} \beta \mathrm{ab}$ as detected by immunoblotting was performed. The serum samples were delipidated (with $0.4 \%$ dextrane sulphate and calcium chloride) and applied to a protein A-Sepharose CL-4B, cyanogen bromide activated column (Sigma, St Louis, Missouri, USA) (binding buffer $3.3 \mathrm{M} \mathrm{NaCl}, 0.15 \mathrm{M}$ glycine, pH 8.5; elution buffer $0.1 \mathrm{M}$ citrate buffer, $\mathrm{pH} 2 \cdot 7$; neutralising buffer $1 \mathrm{M}$ Tris, $\mathrm{pH} 9$ ). The unbound fraction containing human $\mathrm{IgG}_{3}$ and the elution fraction containing the other subclasses were analysed for the presence of $a \beta a b$ by immunoblotting. No differences were detected between the $\operatorname{IgG}_{3}$ a $\beta$ ab levels in the whole serum and the $\mathrm{IgG}_{3}$ fraction. This excluded the possibility of a false negative $\mathrm{IgG}_{3}$ result caused by a competitive inhibition by the other IgG subclasses.

ANTIBODY DETERMINATION BY ELISA

Measurements of IgG a $\beta a b$ and of antibodies against $P$ aeruginosa sonicate by ELISA in the same group of patients have been published previously. ${ }^{1325}$

\section{REPRODUCIBILITY OF THE IMMUNOBLOTTING} ASSAY

The intraday and day-to-day variation were determined after blotted strips were allowed to react with 10 serum samples of low $(n=4)$, medium $(n=3)$, and high $(n=4)$ antibody concentration. Variation was calculated using the formula $\mathrm{SD}=\sqrt{ } \Sigma \mathrm{d}^{2} / 2 \mathrm{n}$ where $\mathrm{SD}$ is the standard deviation, $\mathrm{d}^{2}$ is the sum of squared differences of double determinations of the same sample, and $\mathrm{n}$ is the number of samples.

The intraday variations of the antibody titres of $\mathrm{IgG}_{1-4}$ were $13 \%, 5 \%, 12 \%$, and $18 \%$, and the day-to-day variations were $14 \%, 11 \%, 17 \%$, and $11 \%$, respectively.

\section{STATISTICAL ANALYSIS}

The Mann-Whitney test for unpaired data and the Spearman rank correlation coefficient were used to test the statistical significance of the differences between the groups of patients.

\section{Results}

IGG AND IGG SUBCLASS ANTIBODIES TO $P$ AERUGINOSA CHROMOSOMAL $\beta$-LACTAMASE IgG a $\mathrm{a}$ ab antibodies were present in all $\mathrm{CF}+\mathrm{P}$ patients who were chronically infected with a strain resistant to $\beta$-lactam antibiotics and in three patients with intermittent colonisation with a resistant strain. These antibodies could not be detected by immunoblotting in any of the samples from either the control group of healthy children or from the non-infected (CF-P) patients, nor in samples from four of the seven patients chronically infected with a sensitive strain.

The IgG positive samples were subsequently assayed for $\beta$-lactamase specific subclass antibodies. The a $\mathrm{a} a \mathrm{~b}$ response was most prevalent for subclasses $\operatorname{IgG}_{1}$ and $\mathrm{IgG}_{4}$, being present in $100 \%$ and $79 \%$ of the patients, respectively,
Percentage of positive serum samples (patients) for the specific IgG subclasses of the aßab antibody during chronic lung infection with $P$ aeruginosa

\begin{tabular}{lrccc}
\hline $\begin{array}{l}\text { Duration of chronic } \\
\text { infection (years) }\end{array}$ & $I g G_{1}$ & $I g G_{2}$ & $I g G_{3}$ & $I g G_{4}$ \\
\hline $0-0 \cdot 5$ & 17 & 0 & 0 & 6 \\
$0 \cdot 5-1$ & 29 & 9 & 3 & 11 \\
$1-1 \cdot 5$ & 35 & 11 & 6 & 23 \\
$1 \cdot 5-2$ & 37 & 23 & 9 & 28 \\
$2-3$ & 60 & 29 & 11 & 52 \\
$3-4$ & 71 & 37 & 14 & 60 \\
$4-5$ & 83 & 43 & 14 & 66 \\
$5-7$ & 89 & 43 & 14 & 76 \\
$7-9$ & 96 & 54 & 16 & 79 \\
$9-11$ & 100 & 56 & 16 & 79 \\
\hline
\end{tabular}

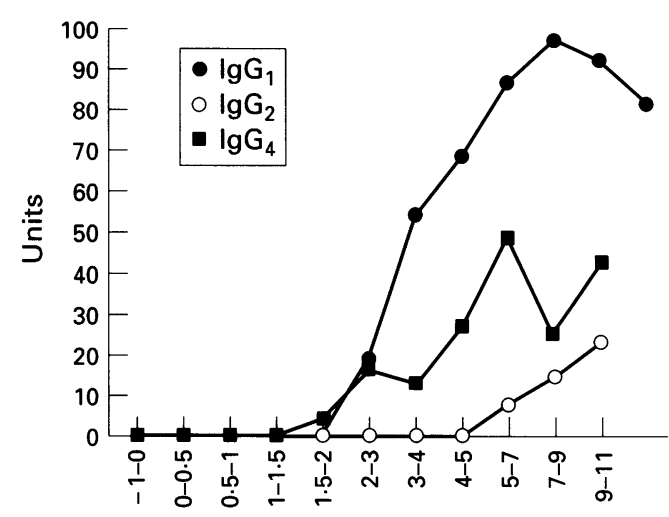

Years from the onset of the chronic infection

Figure 2 Development of IgG subclass aßab antibodies during chronic infection with Pseudomonas aeruginosa in 43 patients with cystic fibrosis (median values).

after 11 years of chronic infection. $\mathrm{IgG}_{2}$ and $\mathrm{IgG}_{3}$ subclasses were detected in $56 \%$ and $16 \%$ of the patients, respectively. These results are shown in the table.

The $\mathrm{IgG}_{1}$ and $\mathrm{IgG}_{4}$ a $\mathrm{\beta ab}$ appeared first, with more than $50 \%$ of the patients being $\operatorname{IgG}_{1}$ and $\mathrm{IgG}_{4}$ positive within $2-3$ years after the onset of the chronic infection. It took seven years to develop $\mathrm{IgG}_{2}$ antibodies in $50 \%$ of the patients and $\mathrm{IgG}_{3}$ antibodies developed in only $16 \%$ of the patients.

During the 11 year period of the study the median IgG antibody levels increased 22-fold, $\mathrm{IgG}_{1}$ 100-fold, IgG 2 22-fold, $\mathrm{IgG}_{4} 45$-fold, and $\mathrm{IgG}_{3}$ median remained zero (fig 2). $\mathrm{IgG}_{3} \mathrm{a} \beta \mathrm{ab}$ were present in only six patients with cystic fibrosis, and all of them became positive in the first three years following the start of the chronic infection. The levels in this group of patients increased 16-fold during the 11 year period of the study.

The IgG aßab levels measured by immunoblotting showed a statistically significant correlation with $\mathrm{a} \beta \mathrm{ab}$ levels determined by ELISA from these patients $(r>0 \cdot 5, \mathrm{p}<0 \cdot 01) .{ }^{13}$

\section{aßab AND LUNG FUNCTION IN PATIENTS WITH} CYSTIC FIBROSIS

Figure 3 shows the development of IgG aßab antibodies in nine patients with good lung function and in nine patients with poor lung function, all of them chronically harbouring a resistant strain.

The $\mathrm{a} \beta \mathrm{ab}$ antibodies appeared in the group of patients with good lung function 18-24 months 


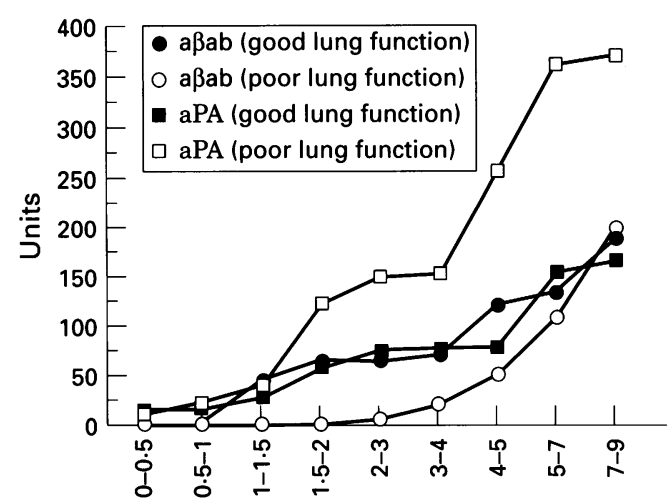

Years from the onset of the chronic infection

Figure 3 Development of IgG $a \beta a b$ and anti Pseudomonas aeruginosa (aPA) antibodies during chronic infection with resistant $P$ aeruginosa strains in nine patients with poor lung function and nine with good lung function.

earlier than in the patients with poor lung function. The levels of $a \beta a b$ antibodies were significantly higher in the group of patients with good lung function after 1.5-2 years $(\mathrm{p}<0.05), 2-3$ years $(\mathrm{p}=0.01)$, and $3-4$ years $(p<0.01)$ from the onset of the chronic infection. The difference was not significant in the later stages of the infection. The levels of IgG a $\beta a b$ subclasses were also higher in the patients with good lung function but the difference between the two groups of patients did not reach statistical significance.

In contrast, median levels of IgG antibodies against $P$ aeruginosa sonicate (standard antigen) were significantly higher in the patients with poor lung function than in those with good lung function after $4-5$ years $(p<0.001)$ and 5-7 years $(p=0.5)$ (fig 3$)$.

\section{Discussion}

A general increase in all subclasses of $\operatorname{IgG}$ antibodies against chromosomal $P$ aeruginosa $\beta$-lactamase was found during the chronic infection of the lungs of patients with cystic fibrosis.

The predominant response against the chromosomal $\beta$-lactamase was $\operatorname{IgG}_{1}$ and $\mathrm{IgG}_{4}$. This is in agreement with studies which show that an early exposure to protein antigens elicits an antibody response predominantly of the $\mathrm{IgG}_{1}$ isotype, whereas $\mathrm{IgG}_{4}$ antibodies increase after prolonged exposure. ${ }^{14}$

$\mathrm{IgG}_{3}$ a $\beta \mathrm{ab}$ antibodies could not be detected in the serum of most of the patients. We therefore conducted a control experiment in which $\mathrm{IgG}_{3}$ was separated from the other antibodies, and found that $\mathrm{IgG}_{3}$ aßab levels in serum samples from patients with cystic fibrosis depleted of other IgG subclasses were similar to those in the whole serum samples. This indicates that the low $\mathrm{IgG}_{3}$ a $\beta \mathrm{ab}$ response is not due to a lack of detection caused by competitive inhibition by other IgG subclasses.

High antibody levels (notably of $\mathrm{IgG}_{2}$ and $\mathrm{IgG}_{3}$ subclasses) against other $P$ aeruginosa antigens are correlated with poor lung function, probably due to immune complex mediated chronic inflammation in the lungs of patients with cystic fibrosis. ${ }^{1226}$ The strong association with the $\mathrm{IgG}_{3}$ subclass may be explained by the strong complement activating ability of $\mathrm{IgG}_{3}$ antibodies which may lead to tissue damage mediated by polymorphonuclear leucocytes. ${ }^{15}$ In contrast with the immune response to other $P$ aeruginosa antigens, a pronounced $\mathrm{IgG}_{4} \mathrm{a} \beta \mathrm{ab}$ response was found. The $\mathrm{IgG}_{4}$ subclass is exceptional in several respects. $\mathrm{IgG}_{4}$ antibodies to various antigens appear to be functionally monovalent and thus produce small, non-precipitating immune complexes while, at the same time, they are unable to fix complement. ${ }^{27}{ }^{28}$

It has also been proposed that high levels of $\mathrm{IgG}_{4}$ antibodies could be a marker for hyperimmunoreactivity. Their presence could be harmless or beneficial by suppressing the immunopathology caused by other antibodies via antagonistic or competitive mechanisms. ${ }^{17}$

The low $\operatorname{IgG}_{3} \mathrm{a} \beta \mathrm{ab}$ and high $\operatorname{IgG}_{4}$ levels in serum samples of patients with cystic fibrosis suggest that the anti- $\beta$-lactamase antibodies probably do not make an important contribution to the immune complex mediated lung tissue damage. This is in contrast to $\mathrm{IgG}_{2}$ and $\mathrm{IgG}_{3}$ antibodies to other $P$ aeruginosa antigens. ${ }^{29}$ The association between a high IgG $_{4}$ immune response and good lung function in patients with cystic fibrosis has also been found for antibodies against protein $\mathrm{H}$ of the $P$ aeruginosa outer membrane. ${ }^{17}$

Another important and surprising observation of our study is the early and high $a \beta a b$ response in patients with good lung function compared with those with poor lung function. This is in direct contrast to that previously observed for antibodies against $P$ aeruginosa sonicate antigen where high levels were correlated significantly with poor lung function. This suggests that patients with an early production of $a \beta a b$ are probably able to inhibit the extracellular $\beta$-lactamase activity. Inhibition of $\beta$-lactamase activity in biofilms by monoclonal antibodies has been shown by our group (unpublished results). The inhibition of $\beta$-lactamase by a $\beta a b$ would lead to the protection of the $\beta$-lactam antibiotic from enzymatic hydrolysis which may result in more efficacious antipseudomonal treatment. The good lung function in the group of patients with high $\mathrm{a} \beta \mathrm{ab}$ levels may therefore be a consequence of in vivo protection by $\beta$-lactamase antibodies. In vitro experiments investigating this hypothesis are in progress at our laboratory.

In conclusion, the $\mathrm{a} \beta \mathrm{ab}$ antibodies appear to have a protective role in patients who develop them early in the course of the chronic infection with $P$ aeruginosa, by inhibiting the extracellular $\beta$-lactamase activity.

The prevalence of $\operatorname{IgG}_{1}$ and $\operatorname{IgG}_{4}$ suggests a minor role for the $a \beta a b$ subclass of antibodies in the immune complex mediated injury of the airway of patients with cystic fibrosis.

Further studies are required to clarify the function and activity of the $\mathrm{a} \beta \mathrm{ab}$ antibodies in patients with cystic fibrosis and chronic infection of the lung with $P$ aeruginosa.

This study was supported by a grant from the Danish Cystic Fibrosis Association. 
1 Pedersen SS, Koch C, Høiby N, Rosendahl K. An epidemic spread of multiresistant Pseudomonas aeruginosa in a cystic
fibrosis centre. $\mathcal{F}$ Antimicrob Chemother 1986;17:505-16.

2 Mouton JW, den Hollander JG, Horrevorts M. Emergence of antibiotic resistance amongst Pseudomonas aeruginosa isolates from patients with cystic fibrosis. If Antimicrob Chemother 1993;31:919-26.

3 Giwercman B, Lambert P, Rosdahl VT, Shand GH, Høiby N. Rapid emergence of resistance in Pseudomonas aeruginosa cystic fibrosis patients due to in vivo selection of stable partially derepressed $\beta$-lactamase producing strains. f Antimicrob Chemother 1990;26:247-59.

4 Ciofu O, Giwercman B, Pedersen SS, Høiby N. Development of resistance as a side-effect of two decades of intensive antipseudomonal treatment in the Danish Cystic Fibrosis Centre. APMIS 1994;102:674-80.

5 Sanders CC, Sanders Jr WE. Clinical importance of inducible $\beta$-lactamase in gram-negative bacteria. Eur $\mathcal{f}$ Clin Microbiol 1987;6:435-7.

6 Livermore DM. Clinical significance of $\beta$-lactamase induction and stable derepression in gram-negative rods. Eur $¥$ Clin Microbiol 1987;6:439-45.

7 Chen HY, Yuan M, Ibrahim-Elmagboul IB, Livermore D. National survey of susceptibility to antimicrobials amongst clinical isolates of Pseudomonas aeruginosa. $\mathcal{F}$ Antimicrob Chemother 1995;35:521-34.

8 Chen HY, Yuan M, Livermore D. Mechanisms of resistance to $\beta$-lactam antibiotics amongst Pseudomonas aeruginosa isolates collected in the UK in 1993. F Med Microbiol 1995;43:300-9.

$9 \mathrm{Li} \mathrm{XZ,} \mathrm{Dzwokai} \mathrm{MA,} \mathrm{Livermore} \mathrm{D,} \mathrm{Nikaido} \mathrm{H.} \mathrm{Role} \mathrm{of}$ the efflux pump(s) in intrinsic resistance of Pseudomonas aeruginosa: active efflux as a contributing factor to $\beta$ lactam resistance. Antimicrob Agents Chemother 1994;38: 1742-52.

10 Giwercman B, Meyer C, Lambert PA, Reimert C, Høiby $\mathrm{N}$. High level $\beta$-lactamase activity in sputum from cystic fibrosis patients during anti-pseudomonal treatment. Antimicrob Agents Chemother 1992;36:71-6.

11 Giwercman B, Rasmussen JW, Ciofu O, Clemmentsen I, Schumacher $\mathrm{H}$, Høiby N. Antibodies against chromoschumacher H, Høiby N. Antibodies against chromo38:2306-10.

12 Koch C, Høiby N. Pathogenesis of cystic fibrosis. Lancet 1993;341:1065-9.

13 Ciofu O, Giwercman B, Rasmussen JW, Pressler T, Pedersen SS, Høiby N. Antibodies against chromosomal Pseudomonas aeruginosa $\beta$-lactamase are markers of the development of resistance of $P$ aeruginos $a$ in patients with cystic fibrosis. F Antimicrob Chemother 1995;35:295-304.

14 Ferrante A, Beard LJ, Feldman RG. IgG subclass distribution of antibodies to bacterial and viral antigens. tribution of antibodies to bacterial and viral
Pediatr Infect Dis $\mathcal{F} 1990 ; 9$ (Suppl 8):16-24.

15 Pressler T, Pedersen SS, Espersen F, Høiby N, Koch C. IgG subclass antibodies to Pseudomonas aeruginosa in sera from patients with chronic $P$ aeruginosa infection investigated by ELISA. Clin Exp Immunol 1990;81:428-34.
16 Pressler T, Pedersen SS, Espersen F, Høiby N, Koch C. IgG subclass antibody responses to alginate from Pseudomonas aeruginosa in patients with cystic fibrosis and chronic

17 Likavcanova E, Lagacé J. Quantitative analysis of the immunoglobulin G subclass responses to Pseudomonas aeruginosa antigens in cystic fibrosis. $\mathcal{F}$ Med Microbiol 1992;36: ginosa an $437-44$.

18 Schaad UB, Lang AB, Wedgwood J, Buehlamnn U, Fuerer E. Serotype-specific serum IgG antibodies to lipopolysaccharides of Pseudomonas aeruginosa in cystic fibrosis: correlation to disease, subclass distribution, and experimental protective capacity. Pediatr Res 1990;27:50813.

19 Høiby N. Pseudomonas aeruginosa infection in cystic fibrosis. Diagnostic and prognostic significance of Pseudomonas aeruginosa precipitins determined by means of crossed immunoelectrophoresis. A survey. APMIS, Section C 1977; 262(Suppl):3-96.

20 Høiby N. Prevention and treatment of the infections in cystic fibrosis. Int $\mathcal{F}$ Antimicrob Agents 1992;229-38.

21 Shand GH, Pedersen SS, Tilling R, Brown MRW, Høiby $\mathrm{N}$. Use of immunoblot detection of serum antibodies in the diagnosis of chronic Pseudomonas aeruginosa lung infection in cystic fibrosis. $\mathcal{F}$ Med Microbiol 1988;27:16977.

22 Towbin H, Staehelin T, Gordon J. Electrophoretic transfer proteins from polyacrylamide gels to nitrocellulose sheets: procedure and some applications. Proc Natl Acad Sci USA 1979;76:4350-4.

23 O'Callaghan $\mathrm{CH}$, Morris A, Kirby SM, Shingler AH. Novel method for detection of $\beta$-lactamases by using a chromomethod for detection of $\beta$-lactamases by using a chromogenic cephalos

24 Jefferis R, Reimer CB, Skvaril F, Molinaro GA. Evaluation of monoclonal antibodies having specificity for human IgG subclasses: results of an IUIS/WHO collaborative study. Immunol Lett 1985;10:223-52.

25 Pedersen SS, Espersen F, Høiby N. Diagnosis of chronic Pseudomonas aeruginosa infection in cystic fibrosis by enPyme-linked immunosorbent assay. 7 Clin Microbiol 1987 ; 25:1830-6.

26 Høiby N, Döring G, Schiøtz PO. The role of immune complexes in the pathogenesis of bacterial infection. Annu complexes in the pathogenesis
Rev Microbiol $1986 ; 40: 29-53$.

27 Van der Zee JS, Van Swieten P, Aalberse RC. Serological aspects of $\mathrm{IgG}_{4}$ antibodies. II. $\mathrm{IgG}_{4}$ antibodies form small, nonprecipitating immune complexes due to functional monovalency. F Immunol 1986;137:3566-71.

28 Van der Zee JS, Van Swieten P, Aalberse RC. Inhibition of complement activation by $\mathrm{IgG}_{4}$ antibodies. Clin $\operatorname{Exp}$ Immunol 1986;64:415-22.

29 Kronborg G, Shand GH, Fomsgaard A, Høiby N. Lipopolysaccharide is present in immune complexes isolated
from sputum in patients with cystic fibrosis and chronic from sputum in patients with cystic fibrosis and chronic
Pseudomonas aeruginosa lung infection. APMIS 1992;100: 175-80. 